Available online on 15.08 .2020 at http://jddtonline.info
ODDT * s

Open $\odot$ Access

Research Article

\title{
Phenolics Contents, Xanthine Oxidoreductase Inhibitory Potential, Antibacterial and Antioxidant Activities of Cachrys libanotis L. Root Extracts
}

\author{
AOUACHRIA Sana ${ }^{\text {*a, }}$, BOUMERFEG Sabah b, BENSLAMA Abderrahim a , BOUSSOUALIM Naouel a, \\ TRABSA Hayat a, BAGHIANI Abderrahmane a \\ a Laboratory of Applied Biochemistry, Faculty of Natural and Life sciences, University Ferhat Abbas Setif 1, Setif 19000, Algeria \\ b Department of Biology, Faculty of Nature and Life Sciences, University Bordj Bou-Arraridj 34000, Algeria
}

\begin{abstract}
To date, no studies have investigated the phytochemical screening and biological activities of Cachrys libanotis L. traditionally used for the treatment of gout and rheumatism. Therefore, we aimed to investigate, for the first time, the phytochemical contents, the xanthine oxidoreductase inhibition, antibacterial, and antioxidant activities of extracts derived from the roots of $C$. libanotis L. Roots were submitted to extraction and fractionation using three different solvents sequentially, in the ascending order of polarity. Subsequently, XOR was purified from bovine milk and its inhibition was evaluated using xanthine/XOR system. The antioxidant activities were assessed employed superoxide scavenging, $\beta$ - carotene bleaching, DPPH scavenging, ferrous iron chelation and FRAP assays). The antibacterial activity was tested by disc diffusion assay against 11 ATCC strains. Extraction and fractionation gave crude extract (CrE), hexane extract (HxE), chloroform extract (ChE), ethyle acetate extract (EAE) and aqueous extract (AqE). EAE exhibited the highest XOR inhibitory effect. CrE exhibited the highest effect as DPPH scavenger. All fractions exhibited a good activity against linoleate oxidation. Both CrE and AqE had an excellent chelating activity. Extracts showed a medium reducing power with greatest value exhibited by EAE. The plant extracts exhibited moderate to good antibacterial activity where the HxE extract had the strongest antimicrobial activity. From the obtained results, $C$. libanotis roots might be helpful in preventing or slowing the progress of gout, and it could be used as an additive in the food industry providing good protection against oxidative damage.
\end{abstract}

Keywords: Cachrys libanotis, polyphenols, oxidative stress, xanthine-oxidoreductase (XOR), antimicrobial.

Article Info: Received 19 June 2020; $\quad$ Review Completed 13 July 2020; $\quad$ Accepted 22 July 2020; Available online 15 August 2020

Cite this article as:

Aouachria S, Boumerfeg S, Benslama A, Boussoualim N, Trabsa H, Baghiani A, Phenolics Contents, Xanthine

Oxidoreductase Inhibitory Potential, Antibacterial and Antioxidant Activities of Cachrys libanotis L. Root Extracts, Journal of Drug Delivery and Therapeutics. 2020; 10(4-s):71-79 http://dx.doi.org/10.22270/jddt.v10i4-s.4278

[1] *Address for Correspondence:

AOUACHRIA Sana, Laboratory of Applied Biochemistry, Faculty of Natural and Life sciences, University Ferhat Abbas Setif 1, Setif 19000, Algeria

\section{INTRODUCTION}

Medicinal plants have been used as sources of medicine in virtually all cultures. Plant materials contain secondary metabolites that polyphenols constitute one of the principal classes 1 . These compounds arouse a big interest by their numerous beneficial effects toward human health. In particular, flavonoids are recognized for their antioxidant, anti-inflammatory and antimicrobial properties 2,3 (RuizCruz et al. 2017). These activities have the most often a link with their antioxidant activity and particularly their capacity to inhibit enzymes responsible for radical generation, scavenge free radicals and chelating metal ions ${ }^{2}$.

Reactive oxygen species (ROS) are well recognized for playing a dual role as both deleterious and beneficial species. Beneficial effects of ROS occur at low/moderate [71] concentrations and involve physiological roles in cellular signaling pathways 4 . In contrast, the generation of ROS beyond the antioxidant capacity of a biological system gives rise to oxidative stress, a deleterious process that can be an important mediator of damage to cell structures, including lipids and membranes, proteins, and DNA 5. Oxidative stress facilitates the development of a variety of human diseases such as inflammations, cardiovascular diseases, neurodegenerative diseases, diabetes mellitus and cancers 6,7 .

Xanthine oxidoreductase (XOR), one of the major sources of ROS, catalyzes the hydroxylation of hypoxanthine to xanthine and xanthine to uric acid, in humans and in a few other uricotelic species 8,9. Hyperuricemia is the most cited pathology involving XOR. A pathological state arises from overproduction of uric acid that forms microscopic crystals CODEN (USA): JDDTAO 
in the capillary vessels of joints. These crystals cause inflammation and sharp pain, which is termed acute gouty arthritis or acute gout 10 . Currently, no clinically effective xanthine oxidase inhibitor for the treatment of hyperuricemia has been developed since allopurinol 11 . Therefore, new inhibitor devoid of undesired side effects has been investigated. Many studies of natural polyphenols, especially flavonoids, in the form of plants or purified extracts show that they could be used as XOR inhibitors.

Over the last few decades, a great interest has developed in searching for antimicrobial drugs from natural products because of the belief that drugs derived from plants are safe compared with synthetic drugs that may have adverse effects besides their high cost 12 . Currently, many bacterial are becoming resistant to the existing antibiotics due to their misuse or repeated use of antibiotics in the treatment of infectious diseases. Therefore, scientists advance in their research findings on the bacterial targets to attack the evolved bacteria and attentions towards to the popular plant extracts and biologically active compounds isolated from the plant ${ }^{13}$.

In Algeria, Apiaceae family has about 55 genera and 130 species. Cachrys is a genus belonging to such family, and it include more than 100 species, widely distributed in Mediterranean basin 14. Cachrys libanotis L. (C. libanotis) have traditional claims for the treatment of rheumatism.

At the time, there are no scientific reports neither on the extraction of polyphenols from the $C$. libanotis roots nor on their biologic activities. The aim of our study is to investigate the phytochemical contents, antioxidant and antibacterial properties and the ability of $C$. libanotis roots extracts to inhibit XOR.

\section{MATERIAL AND METHODS}

The medicinal plant C. libanotis L. was gathered from AinTouta, Batna (Algeria) in November 2010. The voucher specimen was identified by Pr. Oujhih B. Institut of nutrition and agronomy, Batna (Algeria) with the reference number $120 /$ ISVSA/UHL/11. The C. libanotis roots were washed, cut in thin rings, dried in free air and in dark, and powdered using traditional mill. The powder was conserved in glass bottle in dark at ambient temperature until its use.

Bovine milk was obtained from local farm from Guedjel, Setif (Algeria) in February 2011 and stored at $4^{\circ} \mathrm{C}$ until its use.

Eleven bacteria that comprized of Pseudomonas aeruginosa ATCC 27853, Escherichia coli ATCC 25922, Salmonella typhimurium ATCC 13311, Acinetobacter baumanii ATCC 19606, Citrobacter freundii ATCC 8090, Proteus mirabilis ATCC 35659, Klebsiella pneumoniae ATCC 700603, Staphylococcus aureus ATCC 25923, Bacillus cereus ATCC 10876, Enterococcus faecalis ATCC 49452 and Lysteria monocytogenes ATCC 15313 have been chosen for the antibacterial screening. All the strains were the American Type Culture Collection (ATCC) which were obtained from Laboratory of Natural substances (Telemcen, Algeria).

All the other reagents were purchased from Sigma chemicals (Germany) and Fluka.

\section{Purification of bovin milk xanthine oxidoreductase}

The XOR was purified routinely in our laboratory from Bovine milk. The purification includes extraction with butanol, fractionation with ammonium sulfate, and purification by chromatography on heparine-agarose 15 . The XOR concentration was estimated at $450 \mathrm{~nm}$ using the FAD extinction coefficient (36 $000 \mathrm{M}-1 \mathrm{~cm}-1)$ 16. The purity of enzyme was assessed on protein/flavin ratio (PFR $=$ A280 /A450) 17 , and on a $10 \%$ sodium dodecyl sulphatepolyacrylamide gel electrophoresis (SDS-PAGE) ${ }^{18}$. Total and specific activities of bovine milk XOR was assayed spectrophotometrically at $295 \mathrm{~nm}$ following the production of uric acid with an extinction coefficient of $9600 \mathrm{M}^{-1} \mathrm{~cm}^{-1} 19$.

\section{Extraction of phenolics compounds}

The C. libanotis powder was soaked, in 85\% aqueousmethanol with a ratio of plant material and extracting solvent of $1: 10 \mathrm{w} / \mathrm{v}$, under agitation overnight at $4^{\circ} \mathrm{C} 20$. The extract was filtered on filter paper then on sintered glass and the methanol was removed under reduced pressure on a rotavapor below $45^{\circ} \mathrm{C}$. The milk white crude extract was coded as $\mathrm{CrE}$. The $\mathrm{CrE}$ was subjected to fractionation using liquid- liquid extraction. The CrE was successively extracted with different solvents of increasing polarity: hexane for defatting, chloroform for aglycone flavonoids extraction and ethyl acetate for glycoside flavonoids extraction. The obtained organic layer of each partition was evaporated under reduced pressure on a rotavapor below $45^{\circ} \mathrm{C}$ to dryness and to afford hexane, chloroform, ethyle acetate and aqueous fractions coded as ChE, EAE and AqE, respectively. All of these fractions were stored at $4{ }^{\circ} \mathrm{C}$ prior to use (in 2011).

\section{Determination of total phenolics content}

Total phenolics content of CLRE was estimated by FolinCiocalteu reagent 21. This method consists of the phosphotungstic $\left(\mathrm{WO}_{4}^{-2}\right)$-phosphomolybdic $\left(\mathrm{MoO}_{4}{ }^{-2}\right)$ acid (Folin-ciocalteu's reagent, FCR) reduction by the phenolic hydroxyl groups, resulting in the formation of a blue product in alkaline solution. Briefly, $200 \mu \mathrm{l}$ of appropriate dilution of each extract were added to $1 \mathrm{ml}$ of 1:10 diluted FCR. After 4 min, the reaction mixture was neutralized with $800 \mu \mathrm{l}$ of saturated sodium carbonate $(75 \mathrm{~g} / \mathrm{l})$. Subsequently, the shaken mixture was allowed to stand for $2 \mathrm{~h}$ at room temperature, and then measured at $765 \mathrm{~nm}$. Gallic acid (GA, $20-140 \mathrm{mg} / \mathrm{l}$ ) was used for the standard calibration curve. The results were expressed as $\mu \mathrm{g}$ gallic acid equivalent (GAE)/mg of each extract.

\section{Determination of flavonoids content}

The trichloride aluminium $\left(\mathrm{AlCl}_{3}\right)$ method ${ }^{22}$ was used for determination of the flavonoids content of the CLRE, employing the reaction of complex formation between flavonoids and aluminum chloride. Aliquots of $1 \mathrm{ml}$ of each extract were added to equal volumes of a solution of $2 \%$ $\mathrm{AlCl}_{3} .6 \mathrm{H}_{2} \mathrm{O}$ (2 $\mathrm{g}$ in $100 \mathrm{ml}$ methanol). The mixture was vigorously shaken, and absorbance was read at $430 \mathrm{~nm}$ after incubation in dark at room temperature of $10 \mathrm{~min}$. Quercetin (QE, 1-40 mg/l) were used as standards for calibration curve. Flavonoids contents were expressed as $\mu \mathrm{g}$ quercetin equivalent $(\mathrm{QE}) / \mathrm{mg}$ of each extract.

\section{Effect of CLRE on XOR}

The XOR inhibitory activity was carried out using spectrophotometric method, following uric acid production at $295 \mathrm{~nm}{ }^{23}$. The assay mixture consisted of $50 \mathrm{mM}$ airsaturated phosphate buffer $\left(\mathrm{Na}_{2} \mathrm{HPO}_{4} / \mathrm{NaH}_{2} \mathrm{PO}_{4}, \mathrm{pH} 7.4\right.$, and containing $0.1 \mathrm{mM}$ ethylenediaminetetraacetic acid (EDTA)), $0.1 \mathrm{mM}$ xanthine (pH 7.4) and $50 \mu \mathrm{l}$ of corresponding concentration of each extract diluted in buffer or methanol. Control experiments revealed that the methanol did not influence the activity of XOR at this concentration. The reaction was initiated by the addition of enzyme and the inhibition was evaluated after $1 \mathrm{~min}$. Allopurinol was assayed as a positive control. The enzyme activity of the control sample was set to $100 \%$ activity. 


\section{Antioxidant activities}

\section{Effects of CLRE on superoxide generated by xanthine/XOR system}

Superoxide $\left(\mathrm{O}_{2} \bullet-\right)$ generated by the xanthine/XOR system are able to reduce cytochrome c. Effects of CLRE on the generation of $\mathrm{O}_{2} \bullet$ - were determined ${ }^{24}$. The reaction mixture contained xanthine $(100 \mu \mathrm{M})$, horse heart cytochrome c (25 $\mu \mathrm{M})$ in air-saturated phosphate buffer $\left(\mathrm{Na}_{2} \mathrm{HPO}_{4} / \mathrm{NaH}_{2} \mathrm{PO}_{4}\right.$, $50 \mathrm{mM}, \mathrm{pH}$ 7.4) supplemented with $0.1 \mathrm{mM}$ EDTA, and corresponding concentration of each extract diluted in buffer or methanol. The reaction was started by the addition of XOR. After $1 \mathrm{~min}$, reduced cytochrome c was determined at $550 \mathrm{~nm}$ against enzyme-free mixture.

\section{Effects of CLRE on superoxide generated by NADH/PMS system}

Antiradical activity was determined 25 . The assay involves the production of $\mathrm{O}_{2} \bullet$ - from $\mathrm{O}_{2}$, using $\mathrm{NADH}$ as a reductant, and phenazine methosulfate (PMS) as a catalyst, in the presence of an indicator, nitroblue tetrazolium (NBT), which turns blue when reduced by $\mathrm{O}_{2} \bullet-$. The color change can be monitored at $560 \mathrm{~nm}$. Briefly, the reaction mixture consisted of $300 \mu \mathrm{l}$ of buffer $\left(\mathrm{NaH}_{2} \mathrm{PO}_{4} / \mathrm{Na}_{2} \mathrm{HPO}_{4}, \mathrm{pH} 7.8\right), 50 \mu \mathrm{l} \beta$ NADH $(3 \mathrm{mM}), 50 \mu \mathrm{l}$ of varying concentrations of each extract, $50 \mu \mathrm{l} \mathrm{NBT}(1 \mathrm{mM})$ and $50 \mu \mathrm{l}$ PMS $(0.3 \mathrm{mM})$. The reaction was conducted at room temperature for $2 \mathrm{~min}$, and initiated by the addition of PMS for $3 \mathrm{~min}$. Superoxide scavenged was determined by comparing the extent of NBT reduction with controls.

\section{$\beta$-carotene/linoleic acid bleaching assay}

Antioxidant capacity is determined by measuring the inhibition of CLRE compounds and the conjugated diene hydro-peroxides arising from linoleic acid oxidation ${ }^{26}$. A stock solution of $\beta$-carotene/linoleic acid mixture was prepared as follows: $0.5 \mathrm{mg} \beta$-carotene was dissolved in $1 \mathrm{ml}$ of chloroform, and then $25 \mu$ linoleic acid and $200 \mathrm{mg}$ Tween 40 were added in round-bottomed flask. Chloroform was evaporated using a rotavapor. A volume of $100 \mathrm{ml}$ distilled water saturated with oxygen (30 $\mathrm{min}, 100 \mathrm{ml} / \mathrm{min}$ ) was added with vigorous shaking to form emulsion. An aliquot of $350 \mu \mathrm{l}$ of each extract, prepared in methanol and/or distilled water at concentration of $2 \mathrm{mg} / \mathrm{ml}$, were added to $2500 \mu \mathrm{l}$ aliquot of reaction mixture, and the emulsion system was incubated up to $48 \mathrm{~h}$ in dark at room temperature. Control samples $(2 \mathrm{mg} / \mathrm{ml})$ received only the emulsion without any sample, while blank consisted only of corresponding extract or control. After this incubation period, absorbance of the mixtures was measured at $490 \mathrm{~nm}$ after $0 \mathrm{~h}, 1 \mathrm{~h}, 2 \mathrm{~h}, 4 \mathrm{~h}, 6 \mathrm{~h}$, $12 \mathrm{~h}, 24 \mathrm{~h}$ and $48 \mathrm{~h}$ of incubation. The rate of bleaching of $\beta$ carotene was calculated as antioxidant activity (AA).

\section{DPPH scavenging assay}

The DPPH is a purple-colored stable free radical; it becomes reduced to the yellow-colored, diphenyl picrylhydrazine. According to 27 with slight modification, $50 \mu$ of various dilutions of each extract or standards were mixed with 1250 $\mu \mathrm{l}$ of a $0.004 \%$ methanol solution of DPPH. After an incubation period of $30 \mathrm{~min}$ in dark at room temperature, the absorbance of the samples was read at $517 \mathrm{~nm}$. The BHT, gallic acid, quercetin, rutin were used as standards. Lower absorbance of the reaction mixture indicated higher free radical-scavenging activity.

\section{Ferrous iron-chelating assay}

Ferrous iron-chelating activity was measured by inhibition of the formation of $\mathrm{Fe}^{+2}$-ferrozine complex after treatment of test extract with $\mathrm{Fe}^{+2}$, following the method of 28 and ISSN: 2250-1177 modified by ${ }^{29}$. The reaction mixture contained $250 \mu \mathrm{l}$ extract, $50 \mu \mathrm{FeCl}_{2}$ (0.6 mM in water) and $450 \mu \mathrm{l}$ methanol. The control contained all the reaction reagents except the extract. The mixture was shaken and allowed at room temperature for $5 \mathrm{~min}$. un aliquot of $50 \mu \mathrm{l}$ of ferrozine ( $5 \mathrm{mM}$ in methanol) were then added, the mixture shaken again, followed by further reaction at room temperature for $10 \mathrm{~min}$ to complex the residual $\mathrm{Fe}^{+2}$ ion. The absorbance of the $\mathrm{Fe}^{+2}$ ferrozine complex was measured at $562 \mathrm{~nm}$ against a blank contained all the reaction reagents except ferrozine. Lower absorbance indicates a higher chelating power. EDTA and quercetin were used as reference chelators.

\section{Ferric reducing ability of plasma (FRAP) assay}

The total antioxidant potential of each extract was determined using a $\mathrm{Fe}^{+3}$ reducing ability of plasma (FRAP) metho 30 modified by 31 . The FRAP assay measures the change in absorbance at $593 \mathrm{~nm}$ due to the formation of a blue-colored $\mathrm{Fe}^{+2}$ - 2,4,6-Tri(2-pyridyl)-s-triazine (TPTZ) compound by the reaction of colorless $\mathrm{Fe}^{+3}$ and electrondonating antioxidants. The FRAP reagent was prepared by mixing 10 volume of $300 \mathrm{mM}$ acetate buffer (pH 3.6) with one volume of $10 \mathrm{mM}$ TPTZ in $40 \mathrm{mM} \mathrm{HCl}$ and one volume of $20 \mathrm{mM} \mathrm{FeCl}_{3}$. Freshly prepared FRAP reagent was warmed to $37^{\circ} \mathrm{C}$, and a reagent blank reading was taken at $593 \mathrm{~nm}$. Subsequently, $90 \mu \mathrm{l}$ of deionized water and $30 \mu \mathrm{l}$ of sample, water or methanol as appropriate for the reagent blank, were added to the FRAP reagent. The initial blank reading with the FRAP reagent alone was subtracted from the final reading selected of the FRAP reagent with the sample to determine the FRAP value of the sample. All solutions were used on the day of preparation. A standard curve was prepared using different concentrations $(0-2000 \mu \mathrm{M})$ of $\mathrm{FeSO}_{4} .7 \mathrm{H}_{2} \mathrm{O}$. The result was expressed as the concentration of antioxidants having a ferric reducing ability equivalent to that of $1 \mathrm{mM} \mathrm{FeSO}{ }_{4} .7 \mathrm{H}_{2} \mathrm{O}, \mathrm{EC1} 31$. The equivalent concentration to that of $1 \mathrm{mM} \mathrm{FeSO}_{4}$ (EC1) was calculated as the concentration of antioxidant giving absorbance increase$+\mathrm{e}$ in the FRAP assay equivalent to the theoretical absorbance value of $1 \mathrm{mM}$ concentration of $\mathrm{Fe}^{+2}$ solution determined using the corresponding regression equation. In this study the reaction was monitored for $30 \mathrm{~min}$, but the 4 and 30 min readings were selected for calculation of FRAP values. Total antioxidant power (TAP) was calculated from the EC1.

\section{Antibacterial acitivity}

The antibacterial activity of extracts were examined against 11 types of reference bacterial strains obtained from the American Type Culture Collection (ATCC), i.e. Gram: Pseudomonas aeruginosa ATCC 27853, Escherichia coli ATCC 25922, Salmonella typhimurium ATCC 13311, Acinetobacter baumanii ATCC 19606, Citrobacter freundii ATCC 8090, Proteus mirabilis ATCC 35659, Klebsiella pneumoniae ATCC 700603.Gram ${ }^{+}$: Staphylococcus aureus ATCC 25923, Bacillus cereus ATCC 10876, Enterococcus faecalis ATCC 49452, Lysteria monocytogenes ATCC 15313. The microorganisms were cultured overnight at $37^{\circ} \mathrm{C}$ in nutrient agar.

A $100 \mathrm{mg} / \mathrm{ml}$ solution of the EAE, ChE and AqE were prepared by dissolving the extract in sterile distilled water. The $\mathrm{CrE}$ and $\mathrm{HxE}$ were dissolved in $50 \%$ and $100 \%$ dimethyl sulfoxide (DMSO) to achieve a concentration of 100 $\mathrm{mg} / \mathrm{ml}$. The resulting solutions were sterilized by filtration $(0.45 \mu \mathrm{m})$.

A fresh bacterial inoculum was suspended in sterile normal saline until turbidity was equivalent to 0.5 McFarland standard $\left(1.5 \times 10^{8} \mathrm{CFU} / \mathrm{ml}\right)$. 
Mueller-Hinton agar medium was prepared and poured in Petri dishes. Next day, from appropriate concentration $(1.5 \times$ $10^{8} \mathrm{CFU} / \mathrm{ml}$ ), the bacterium was subcultured on the media by streaking the bacterial suspension using a cotton swab. Discs (each $6 \mathrm{~mm}$ in diameter) were made in agar plates. A volume of $20 \mu \mathrm{l}$ of each plant extracts was added to each disc. Distilled water and DMSO were used as a negative control while Gentamicin were used as positive control. The inoculated dishes were covered and incubated at $35{ }^{\circ} \mathrm{C}$ for 24 $\mathrm{h}$, then the diameter of the bacterial inhibition zone was measured to evaluate the antibacterial activity ${ }^{32}$. Each plant extract was examined in duplicate.

\section{Statistical analysis}

The results were expressed as mean \pm standard deviation (SD) of three replicates. Where applicable, the data were subjected to one-way analysis of variance (ANOVA) and the differences between samples were determined by Duncan's multiple comparison test and Tukey's multiple comparison test. The Pearson correlation analysis was performed between antioxidant activity and total phenolic and flavonoids contents, and, in the other hand, between total phenolic content and flavonoids content. All results were analysed using GraphPad Prism version 5.00. $p$ value $\leq 0.05$ was regarded as significant.

\section{RESULTS AND DISCUSSION}

\section{Total phenolics and flavonoids contents}

The extraction yields calculated showed that $\mathrm{CrE}$ registered a yield of $12.14 \pm 0.34 \%$. The values of total phenolics and flavonoids contents were showed in Table 1 . The highest levels of both polyphenols and flavonoids were recorded by EAE $(82.23 \pm 2.03 \mu \mathrm{g} \mathrm{GAE} / \mathrm{mg}$ of extract and $0.63 \pm 0.28 \mu \mathrm{g}$ $\mathrm{QE} / \mathrm{mg}$ of extract, respectively).

Table 1: Total polyphenols and flavonoids contents of CLRE

\begin{tabular}{|c|c|c|c|c|c|}
\hline Extract & Yeilds (\%) & $\begin{array}{c}\text { Total phenols } \\
\text { Content ( } \mu \text { g GAE } / \mathrm{mg} \\
\text { of extract) }\end{array}$ & $\begin{array}{c}\text { Flavonoids } \\
\text { Contents }(\mu \mathrm{g} \mathrm{QE} / \mathrm{mg} \\
\text { of extract) }\end{array}$ & $\begin{array}{c}\text { Total phenols } \\
\text { Content }(\mathrm{mg} / 100 \mathrm{~g} \\
\text { of dry powder }\end{array}$ & $\begin{array}{c}\text { Flavonoids } \\
\text { Contents }(\mathrm{mg} / 100 \mathrm{~g} \\
\text { of dry powder }\end{array}$ \\
\hline $\mathrm{CrE}$ & $12.14 \pm 0.34$ & $15.64 \pm 3.59$ & $0.10 \pm 0.01$ & $188.94 \pm 0.04$ & $1.23 \pm 0.00$ \\
\hline ChE & $0.26 \pm 0.01$ & $49.64 \pm 6.01$ & $0.11 \pm 0.01$ & $13.69 \pm 0.00$ & $0.02 \pm 0.00$ \\
\hline EAE & $0.20 \pm 0.01$ & $83.23 \pm 2.03$ & $0.63 \pm 0.28$ & $16.44 \pm 0.00$ & $0.13 \pm 0.05$ \\
\hline $\mathrm{AqE}$ & $7.38 \pm 0.10$ & $14.98 \pm 2.00$ & $0.05 \pm 0.01$ & $108.97 \pm 0.01$ & $0.40 \pm 0.08$ \\
\hline
\end{tabular}

Values are expressed as mean \pm SD $(n=3)$.

A correlation analysis was performed on total phenolics and flavonoids contents using Pearson's correlation coefficient. Pearson's correlation coefficient was positively high if 0.610 $<\mathrm{r}<0.974$ and negatively high if $-0.610<\mathrm{r}<-0.974{ }^{33}$. As expected, total phenolics content of $\mathrm{CrE}$ and fractions had strong positive correlation with flavonoids content $(\mathrm{r}=$ 0.893). This indicates that flavonoids are the dominating phenolic group in $\mathrm{CrE}$ and its fractions.

\section{Purification of bovine milk xanthine oxidoreductase}

The freshly purified bovine milk XOR showed an ultraviolet / visible spectrum with three major peaks at 280, 325 and 450 $\mathrm{nm}$, with yield of $17.97 \mathrm{mg} / \mathrm{l}$ and $\mathrm{A}_{280} / \mathrm{A}_{450}$ (PFR) of 5.03 indicating a high degree of purity 17 . Run on SDS-PAGE, purified enzyme showed quite similar patterns with one major band of approximately $150 \mathrm{KDa}$. Total XOR and XO specific activities were $2261 \mathrm{nmsole} / \mathrm{min} / \mathrm{mg}$ and 2011 nmole/min/mg of enzyme, respectively. These results are similar to those obtained by 15,23 .

\section{Effect of CLRE on XOR}

All extracts of C. libanotis roots inhibited XOR in a concentration-dependent manner. As figure 1 showed, the most potent XOR inhibitors observed were EAE and ChE with an $\mathrm{IC}_{50}$ of $0.11 \pm 0.01$ and $0.14 \pm 0.00 \mathrm{mg} / \mathrm{ml}$, respectively, followed by $\mathrm{CrE}\left(\mathrm{IC}_{50}=1.05 \pm 0.00 \mathrm{mg} / \mathrm{ml}\right)$ then $\mathrm{AqE}\left(\mathrm{IC}_{50}=\right.$ $2.35 \pm 0.08 \mathrm{mg} / \mathrm{ml}$ ). Interestingly, EAE showed a strong inhibitory effect toward XOR which was similar to that of the allopurinol $\left(\mathrm{IC}_{50}=0.009 \pm 0.00 \mathrm{mg} / \mathrm{ml}\right.$ ). Moreover, at high doses of the $\mathrm{CrE}$, $\mathrm{ChE}$ and AqE, XOR would be significantly inhibited $(p \leq 0.05)$.

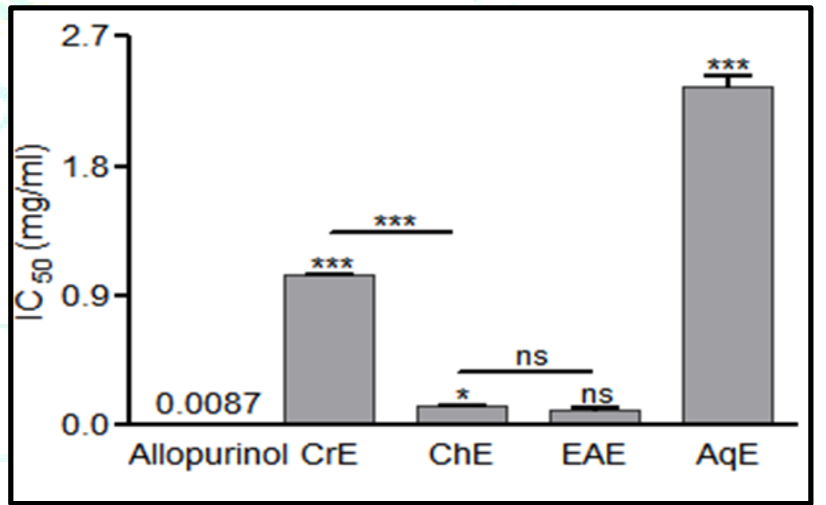

Figure 1: Inhibitory concentration of CLRE for $50 \%$ of XOR activity (IC50). Comparison was realised against allopurinol. *: $p \leq 0.05,{ }^{* * *}: p \leq 0.001$, and ns: non significance.

Since flavonoids are a group of polyphenolic compounds, which have been reported to possess XOR inhibitory activity, the presence of phenolics and flavonoids content in the CLRE would have contributed towards XOR inhibition. The correlation analysis indicated that there is a high negative correlation between total phenolics content and IC 50 of XOR inhibitory activity $(\mathrm{r}=-0.7919)$ but it was weak with flavonoids content $(r=-0.5787)$. In the view of this correlation, a good part of the XOR inhibitory activity induced by $\mathrm{CrE}$ and fractions can be linked up to the content of polyphenols. In addition, these results showed that the XOR inhibition could be linked not only on the polyphenols and flavonoids contents, but also to the nature of these compounds 34 . Our findings are in agreement with studies showing that polyphenols inhibit the XOR 23,35. 


\section{Effect of CLRE on superoxide generated by xanthine/XOR system}

The $\mathrm{O}_{2} \bullet$ - scavenging activity of the CLRE are markedly increased with increasing concentrations. The obtained results showed that $\mathrm{ChE}$ present the most potent $\mathrm{O}_{2}$ scavenger with an IC 50 of $0.22 \pm 0.00 \mathrm{mg} / \mathrm{ml}$ followed by EAE with $\mathrm{IC}_{50}$ of $0.47 \pm 0.00 \mathrm{mg} / \mathrm{ml}$. While $\mathrm{CrE}$ present a high IC $\mathrm{C}_{50}$ of $2.69 \pm 0.08 \mathrm{mg} / \mathrm{ml}, \mathrm{IC}_{50}$ value of AqE could not be determined, since the highest concentration tested did not lead to inhibition as high as $50 \%$. The reduction of cytochrome $\mathrm{c}^{+3}$ was almost totally inhibited by SOD (330 $\mathrm{U} / \mathrm{mL}$ ).

Since an inhibitory effect on the enzyme itself would also lead to a decrease in reducing cytochrome $\mathrm{c}^{+3}$, we cannot confirm that this decrease in presence of extracts is only due to their $\mathrm{O}_{2} \bullet-$ scavenger abilities. In this regard, the previous results were compared with that obtained from extracts inhibitory effect on XOR, demonstrating that CrE, ChE and EAE exhibited a dual effect (XOR inhibition and $\mathrm{O}_{2} \bullet-$ scavenger) on cytochrome $\mathrm{c}^{+3}$ reduction. These extracts present a predominance of an enzyme inhibition activities rather than a scavenging of $\mathrm{O}_{2} \bullet-$. In contrast, AqE shows an inhibitory effect on the enzyme only (Figure 2). According to the classification of $36, \mathrm{CrE}, \mathrm{ChE}$ and EAE were selected in category $\mathrm{C}$ (XO inhibitors with an additional superoxide scavenging activity), and AqE in category B (XO inhibitors without any additional superoxide scavenging activity).

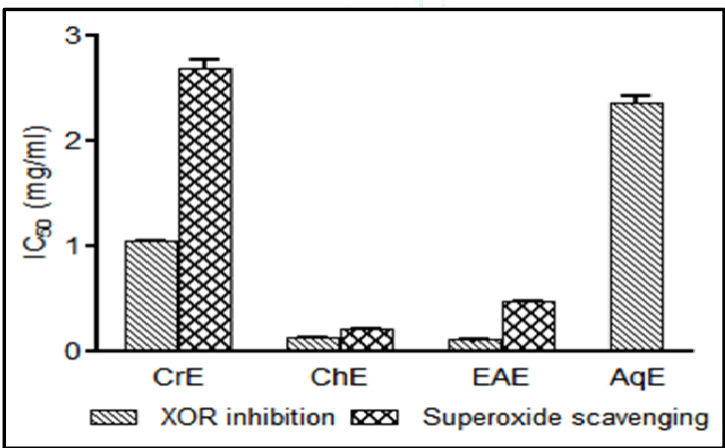

Figure 2: Comparison between $\mathrm{IC}_{50}$ of CLRE resulting from XOR inhibition and $\mathrm{O}_{2} \bullet$ - scavenging assays.

\section{Effects of CLRE on superoxide generated by NADH/PMS} system

To confirm the scavenger effect of CLRE on $\mathrm{O}_{2} \bullet-$, the NBT assay was carried out. The different concentrations of extracts showed antiradical activity in a dose-dependent manner. At concentration from 120 to $300 \mu \mathrm{g} / \mathrm{ml}$, ChE inhibited the reduction of NBT by 29.15 to $75.15 \%$, showing the high scavenging activity followed by EAE and CrE (Figure $3)$.

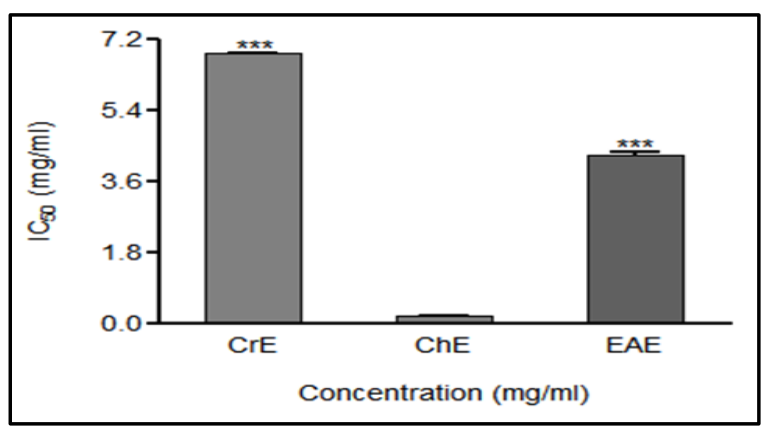

Figure 3 : Scavenging activity of CLRE on $\mathrm{O}_{2} \bullet-$ generated by NADH/PMS system. Comparison was realised against ChE, ***: $p \leq 0.001$.
An order similar to that found in $\mathrm{O}_{2} \bullet$ - scavenging using xanthine/XOR system. Compared to result obtained in $\mathrm{O}_{2} \bullet$ scavenging using xanthine/XOR system, we can suggest that, the possible inhibition mechanism of both NBT and cytochrome c reduction was through direct $\mathrm{O}_{2} \bullet$-scavenging action not XOR inhibition. However, for the $\mathrm{ChE}$, the mechanism occurred through dual action of XOR inhibition and $\mathrm{O}_{2} \bullet-$ scavenging with favor of XOR inhibition. The antioxidant properties of flavonoids are effective mainly via the scavenging of $\mathrm{O}_{2} \bullet-37$. However, through the correlation analysis, the $\mathrm{O}_{2} \bullet-$ scavenging activity of $\mathrm{CrE}$ and fractions did not point to any correlation with phenolic compounds content $(r=-0.3885)$ and flavonoids content $(r=0.1103)$. The lack of correlation indicated that phenolic compounds and flavonoids played a weak role on $\mathrm{O}_{2} \bullet$ - scavenging activity.

\section{$\beta$-carotene/linoleic acid bleaching assay}

The mechanism of $\beta$-carotene bleaching is a free-radical mediated phenomenon resulting from the hydroperoxides formed from linoleic acid. $\beta$-carotene undergoes rapid discoloration in the absence of an antioxidant. The linoleic acid free radical formed upon the abstraction of a hydrogen atom from one of its diallylic methylene groups attacks the highly unsaturated $\beta$-carotene molecules. As $\beta$-carotene molecules lose their double bonds by oxidation; the compound loses its chromophore and characteristic orange color, which can be monitored spectrophotometrically 38 . Presence of different antioxidants can hinder the extent of $\beta$ carotene bleaching by neutralizing the linoleate free radical and other free radicals formed in the system. Hydroperoxides formed in this system will be degraded by the antioxidants from the extract/fractions. Accordingly, the absorbance decreased rapidly in samples without antioxidant whereas, in the presence of an antioxidant, they retained their color, and thus absorbance, for a longer period of time 39. The bleaching kinetics of $\beta$-carotene in the presence $\mathrm{CrE}$, fractions, controls and standard are shown in figure 4 . The $\mathrm{CrE}$, fractions, controls and standard inhibited the oxidation of $\beta$-carotene. This effect is due to either the inhibition of linoleic acid peroxidation or the radical scavenging of hydroperoxides formed during the peroxidation of linoleic acid.

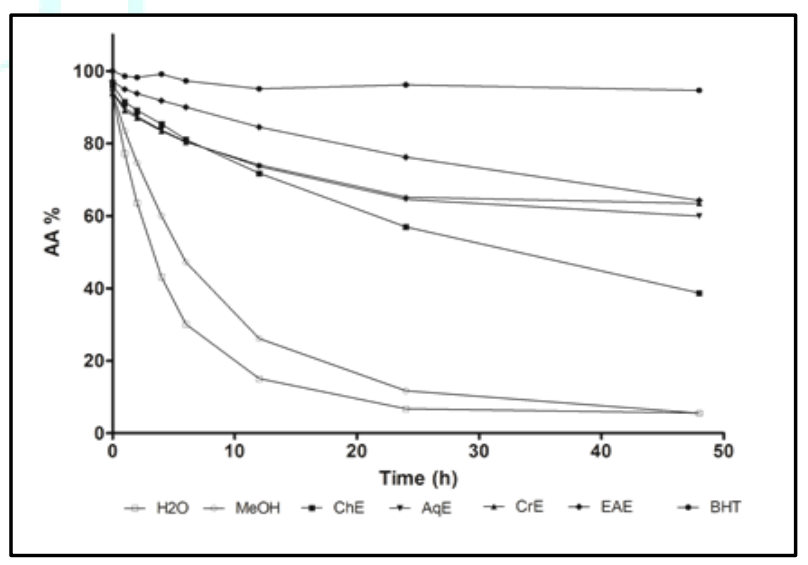

Figure 4 : Kinetic of antioxidant activity of CLRE, water, methanol and BHT during 48h, using a $\beta$-carotene/ linoleic acid bleaching assay. Values are expressed as means of triplicate.

The EAE exhibited the highest AA (76.21 $\pm 6.12 \%)$, which was near to that of BHT $(96.17 \pm 2.05 \%)$, following by $\mathrm{CrE}$ and AqE with, approximately, an equal AA (65.17 $\pm 1.88 \%$ and $64.57 \pm 1.68 \%$, respectively). Whereas, ChE exhibited the lowest AA (56.95 $\pm 3.40 \%$ ) (Figure 5). 


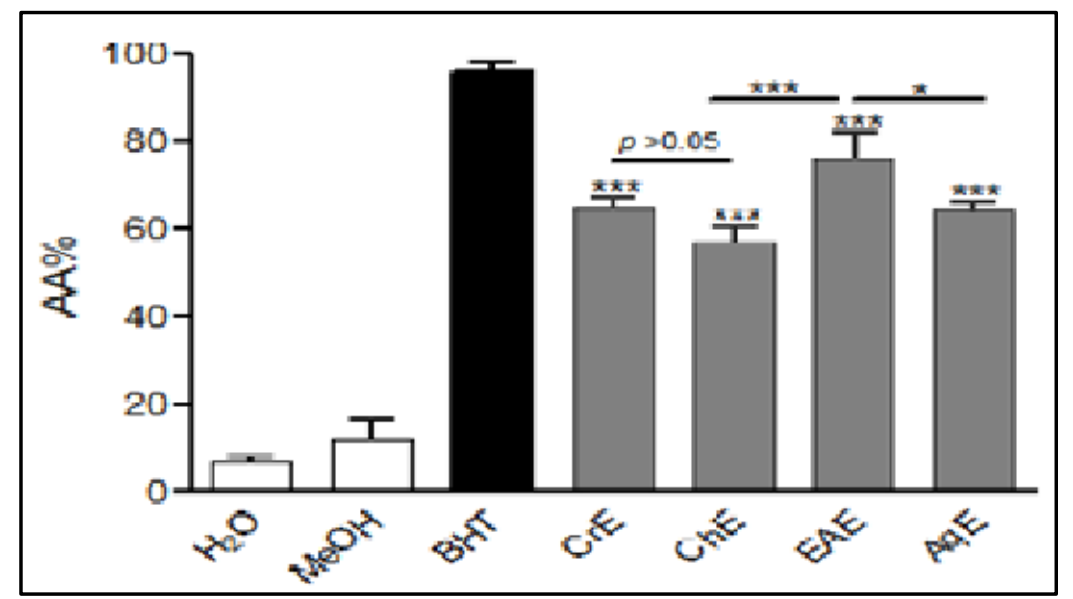

Figure 5 : Antioxidant activity of CLRE compared with BHT, methanol and water. Comparison was realised against positive control (BHT); ${ }^{*} 0.05,{ }^{* * *} \mathrm{p} \leq 0.001$.

With reference to correlation analysis, there was a weak correlation between phenolic compounds contents and antioxidant activity based on $\beta$-carotene bleaching assay $(\mathrm{r}=$ 0.5309). This showed that the phenolic compounds from the plant in this study weakly inhibited the oxidation of $\beta$ carotene by hydroperoxides. Possibly, other bioactive compounds were responsible for the antioxidant activity determined 40 . Our findings were consistent with the studies conducted 41,42 , that showed that there was no correlation between antioxidant activity based on $\beta$-carotene bleaching assay and total phenolics contents.

\section{DPPH scavenging asssay}

The DPPH radical scavenging activity of extracts increased with concentration. As table 2 showed, CrE was found to exhibit the greatest scavenger activity with IC50 of $(0.41 \pm$ $0.01 \mathrm{mg} / \mathrm{ml})$, followed by that of EAE $(0.57 \pm 0.01 \mathrm{mg} / \mathrm{ml})$. The radical scavenging activity in the plant extracts decreased in the following order: $\mathrm{CrE}>\mathrm{EAE}>\mathrm{AqE}>\mathrm{ChE}$. The DPPH scavenging activities of all plant extracts were significantly lower than that of BHT ( $\mathrm{p} \leq 0.001)$.

Table 2: DPPH scavenging activity of CLRE and standards.

\begin{tabular}{llll}
\hline Standards & IC $_{50}(\mathrm{mg} / \mathrm{ml})$ & Extracts & IC $_{50}(\mathrm{mg} / \mathrm{ml})$ \\
\hline BHT & $0.09 \pm 0.00$ & CrE & $0.41 \pm 0.01^{* * *}$ \\
GA & $1.27 \pm 0.00^{\#}$ & ChE & $1.14 \pm 0.02^{* * *}$ \\
Quercetin & $2.57 \pm 0.00^{\#}$ & EAE & $0.59 \pm 0.01^{* * *}$ \\
Rutin & $5.59 \pm 0.00^{\#}$ & AqE & $0.69 \pm 0.01^{* * *}$ \\
\hline
\end{tabular}

$\#: \mu \mathrm{g} / \mathrm{ml}$. Comparison was realised against BHT, ${ }^{* * *}: \mathrm{p} \leq 0.001$.

Several studies reported that the phenolic contents plant extracts are responsible for their radical scavenging activity. The phenolic compounds may act as free radical scavengers because of their hydrogen-donating ability and scavenging ability ${ }^{43}$. Both total phenolic content and flavonoids content in $\mathrm{CrE}$ and fractions had no correlation with IC50 of DPPH scavenging activity $(r=-0.2302 ; r=-0.2192$, respectively). It might be supposed that phenolic compounds in $\mathrm{CrE}$ and fractions were not the major contributor in its antioxidant activity by DPPH scavenging assay. Moreover, this may be linked to the assumption that most of the flavonoids were in their glycoside forms and thus less effective compared to their aglycone forms 44. It means that polyphenols and flavonoids had no influence in antioxidant activity by DPPH scavenging method.

\section{Ferrous iron-chelating assay}

The chelating effects of the extracts on ferrous increased as a function of concentration. Surprisingly, CLRE exhibited an excellent chelating ability, which was even much better than that of quercetin $($ IC50 $=950.4 \pm 11.0 \mu \mathrm{g} / \mathrm{ml}$ ). The $\mathrm{CrE}$ and AqE showed the highest chelating activity with an IC50 values of $52.6 \pm 0.3$ and $52.7 \pm 0.2 \mu \mathrm{g} / \mathrm{ml}$, respectively, followed by EAE $(503.5 \pm 3.8 \mu \mathrm{g} / \mathrm{ml})$ and $\mathrm{ChE}(635.5 \pm 18.4$ $\mu \mathrm{g} / \mathrm{ml}$ ). In other term, even with a dosage as low as 110 ISSN: 2250-1177 $\mu \mathrm{g} / \mathrm{ml}$, the chelating ability of the $\mathrm{CrE}$ and AqE fraction reached over $90 \%$ in this assay. Moreover, both CrE and AqE had a near chelating effect than that of EDTA, demonstrating thus the excellent chelating ability of these extracts (Figure 6). As a control, EDTA exhibited, compared with those of extracts, strong chelating ferrous iron ability (IC50 $=6.1$ $\mu \mathrm{g} 0 / \mathrm{ml}$ ) which is close to that found by $29,5.6 \mu \mathrm{g} / \mathrm{ml}$.

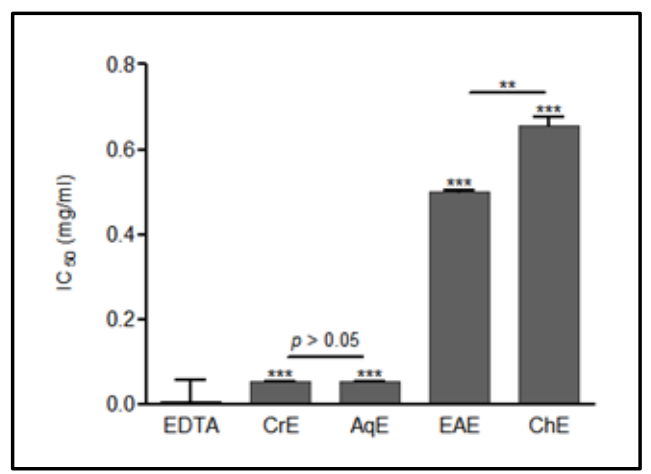

Figure 6 : Ferrous iron-chelating ability of CLRE and EDTA. Comparison was realised against EDTA; ${ }^{* *}$ : $p \leq 0.01,{ }^{* * *}$ : $p \leq$ 0.001 . 
Noting that AqE contained the lowest amount of both total phenolics and flavonoids compared to $\mathrm{CrE}$, ChE and EAE ; however, it exhibited the highest chelating activity. This result can be explained by the work of 45 , indicating that plant fractions induce chelating activity proportional to the polarity of their solvents.

The relationship between polyphenol complexation for a range of metals has been widely reported in the literature. As a class, they tend to be good metal complexing agents. It is the structure of polyphenols that ultimately determines their effectiveness as complexing agents as well as the number of metal cations they can bind. Binding ratios vary depending on the molecules involved 46. The possible mechanism of chelating $\mathrm{Fe}^{+2}$ by phenolics is as follows: phenolics, which possess a number of hydroxyl groups, firstly lose protonated hydrogen and then form strong coordination oxygen ion complexes with a ferrous ion 46 .

According to the literature, studies undertaken in recent years have demonstrated that the polyphenols and flavonoids can be excellent chelators for iron and copper 47 . However, through the correlation analysis, the chelating activity of $\mathrm{CrE}$ and fractions did not point to any correlation with phenolic compounds content $(r=0.4481)$. The lack of correlation indicated that phenolic compounds and flavonoids played a weak role on the ferrous chelating activity. This result let us suggest that the noticeable chelating activity of $C$. libanotis roots was the result of synergic effect of all fractions' compounds that include a high amount of nonphenolic hydrosoluble compounds. Our results are consistent with those found by 48 who reported that there is no correlation between phenolic compounds and flavonoids contents of the extract from the in vitro grown Trifolium pretense and ion chelating activity.

\section{Ferric reducing ability of plasma (FRAP) assay}

In contrast to method of 30 , the absorbance did not stabilise after $4 \mathrm{~min}$. Therefore, the measurements were continued for $30 \mathrm{~min}$, in agreement with method of 31 . Some extracts even doubled their initial absorbance after 30 min of reaction, as was the case with CrE and EAE. However, while ChE showed only a minor increase beyond $4 \mathrm{~min}$, AqE showed a high increase (Figure 7). The CLRE increased their reducing power with time might imply an ability to maintain their antioxidant activity for longer times, helping to maintain an adequate antioxidant status in vivo. Another remark that the reducing powers of CLRE increased with the increase in concentration.

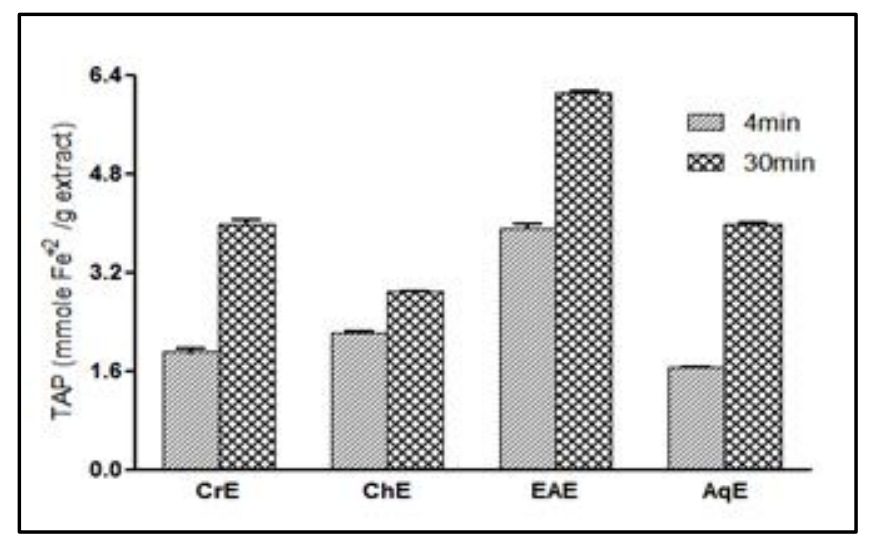

Figure 7: Comparison between TAP of CLRE at 4 min and 30 min. TAP values were expressed as mean \pm SD of duplicate.

Results of reducing power of extracts and gallic acid is presented in table 3. At 4 min, EAE showed the highest TAP, referring a good reducing power. The EAE was followed by $\mathrm{ChE}, \mathrm{CrE}$ and AqE with TAP lower than that of gallic acid. However, this order was changed at $30 \mathrm{~min}$ to: EAE > $\mathrm{CrE}=\mathrm{AqE}>\mathrm{ChE}$. The $\mathrm{ChE}$ appears having the strongest reducing power compared to $\mathrm{CrE}$ and $\mathrm{AqE}$ at $4 \mathrm{~min}$; however, at end of reaction (30 min), it presented the less reducing power. The matter might return to the nature of phenolic and non-phenolic compounds of each extract.

Table 3 : TAP values at $4 \mathrm{~min}$ and $30 \mathrm{~min}$ of reaction with the FRAP assay

\begin{tabular}{lcc}
\cline { 2 - 3 } & $\begin{array}{c}\text { TAP (4mn) } \mathbf{~ m M ~ F e} \\
\text { /g extract }\end{array}$ & $\begin{array}{c}\text { TAP (30 mn) } \mathbf{~ m M ~ F e} \\
\text { /g extract }\end{array}$ \\
\hline $\mathrm{GA}$ & $21.29 \pm 1.18$ & $28.31 \pm 1.46$ \\
$\mathrm{CrE}$ & $1.90 \pm 0.07$ & $3.99 \pm 0.07$ \\
$\mathrm{ChE}$ & $2.22 \pm 0.02$ & $2.90 \pm 0.00$ \\
$\mathrm{EAE}$ & $3.92 \pm 0.07$ & $6.12 \pm 0.02$ \\
$\mathrm{AqE}$ & $1.66 \pm 0.01$ & $3.99 \pm 0.01$ \\
\hline
\end{tabular}

The reducing power and the total phenolic content of CLRE showed a strong negative correlation at $4 \mathrm{~min}(\mathrm{r}=-0.9687$; $p=0.0313$ ). Moreover, a high negative correlation was found between the reducing power and flavonoids contents $(\mathrm{r}=$ 0.9404). Therefore, it can be said that the reducing power can be attributed to phenolics, especially to flavonoids. This result is in agreement with several reports indicating that the phenolic compounds contribute significantly to the reducing power in different medicinal plants 49,50 . The results elucidate that polyphenolic contents of the CLRE appear to function as good electron and hydrogen donors and therefore should be able to terminate radical chain reaction by converting free radicals to more stable products.

\section{Antibacterial activity}

Infectious diseases are the top and second leading causes of death in low- and high-income countries. There is even a growing association between communicable (infectious) and non-communicable diseases 51 . The health problems related to microbial infections are seriously exacerbated by the widespread of antibiotic resistance and the lack of effective new therapeutics. Therefore, we investigated the antimicrobial activity of extracts obtained from C. libanotis roots.

The antibacterial activity were investigated using agar disc diffusion method against selected human pathogens. This method was known for its simplicity, its reproducibility and its effectiveness to test the sensitivity of the bacteria.

The screening of antibacterial activity (Table 4) showed that the inhibition diameters varied from 7 to $12 \mathrm{~mm}$ for the studied strains. The HxE was sensitive to all strains and the higher inhibitory diameter was obtained for Staphylococcus aureus. The AqE did not produce inhibition zones against any type of tested bacteria; whereas CrE produced inhibition zone diameter aginst Pseudomonas aeruginosa, Staphylococcus aureus, Bacillus cereus, respectively. Both ChE and EAE showed an antibacterial effect versus Bacillus cereus, Enterococcus faecalis and Lysteria monocytogenes. The inhibitory diameters of all extracts are lower than the inhibition diameters of Gentamicin for all strains. Interestingly, the results indicated that $\mathrm{Gram}^{+}$bacteria are more sensitive to $C$. libanotis compared to Gram- bacteria, which proved to be more resistant to the extracts treatment. 
Table 4: Screening of the antimicrobial activity of the extracts of $C$. libanotis against Gram positive and negative bacteria.

\begin{tabular}{|c|c|c|c|c|c|}
\hline \multirow{2}{*}{ Bacteria } & \multicolumn{5}{|c|}{ Main inhibition zone (mm) } \\
\hline & $\mathrm{CrE}$ & HxE & ChE & EAE & $\mathbf{A q}$ \\
\hline \multicolumn{6}{|l|}{ Gram- } \\
\hline Pseudomonas aeruginosa ATCC 27853 & $7.5 \pm 0.5$ & $10.0 \pm 0.5$ & - & - & 0 \\
\hline Escherichia coli ATCC 25922 & 0 & $7.5 \pm 0.5$ & - & - & 0 \\
\hline Salmonella typhimurium ATCC 13311 & 0 & 0 & 0 & 0 & 0 \\
\hline Acinetobacter baumanii ATCC 19606 & 0 & 0 & 0 & 0 & 0 \\
\hline Citrobacter freundii ATCC 8090 & 0 & 0 & 0 & 0 & 0 \\
\hline Proteus mirabilis ATCC 35659 & 0 & 0 & 0 & 0 & 0 \\
\hline Klebsiella pneumoniae ATCC 700603 & 0 & 0 & 0 & 0 & 0 \\
\hline Gram+ $^{+}$ & & & & & 0 \\
\hline Staphylococcus aureus ATCC 25923 & $9.5 \pm 0.5$ & $11.5 \pm 0.5$ & - & - & 0 \\
\hline Bacillus cereus ATCC 10876 & $7.5 \pm 0.0$ & $10.0 \pm 0.0$ & $9.3 \pm 0.3$ & $9.5 \pm 0.5$ & 0 \\
\hline Enterococcus faecalis ATCC 49452 & 0 & $10.0 \pm 0.0$ & $8.8 \pm 0.3$ & $8.0 \pm 0.0$ & 0 \\
\hline Lysteria monocytogenes ATCC 15313 & 0 & $8.0 \pm 0.0$ & $8.0 \pm 0.0$ & $7.0 \pm 0.0$ & 0 \\
\hline
\end{tabular}

Values are expressed as mean \pm SD of duplicate.

\section{CONCLUSION}

In conclusion, although $C$. libanotis roots might consider as poor source for polyohenols, it showed a good XOR inhibition and free radical scavenger that might be helpful in preventing or slowing the progress of gout and thus providing initial data that justify the use and importance of C. libanotis roots in folkloric medicine. Otherwise, C. libanotis roots exhibited a strong ferrous iron-chelating and inhibition of linoleic acid oxidation suggesting that this plant could be used as an additive in the food industry providing good protection against oxidative damage. These results can be useful as a starting point of view for further applications of $C$. libanotis roots or its constituents in area of healthcare after performing clinical in vivo researches.

\section{Acknowledgement}

This work was supported by the Algerian Ministry of Higher Education and Scientific Research (MESRS) project CNEPRU $\mathrm{N}^{\circ}$ F01220110063. We would like to thank Pr. Oudjhih Bachir, Department of agronomy, University Batna 1, Algeria, for the identification of the plant material.

\section{Conflict of Interest}

The authors have no conflicts of interest to declare.

\section{REFERENCES}

1. Hussein RA, El-Anssary AA. Plants secondary metabolites: the key drivers of the pharmacological actions of medicinal plants. In : Builders P, editor. Herbal Medecine. IntechOpen; 2018. p 13-30.

2. Negrào R, Faria A. Natural polyphenols as anti-oxidant, antiinfammatory and anti-angiogenic agents in the metabolic syndrome. In: Soares R, Costa C, editors. Oxidative stress, inflammation and angiogenesis in the metabolic syndrome. Springer; 2009. p 147-180.

3. Ruiz-Cruz S, Chaparro-Hernández S, Hernández- Ruiz KL, CiraChávez LA, Estrada-Alvarado MI, Gassos Orteg LE, et al. Flavonoids: Important Biocompounds in Food. In Justino J, editor. Flavonoids - From Biosynthesis to Human Health. IntechOpen; 2017. p 353-369.
4. Di Meo S, Reed TT, Venditti P, Victor VM. Role of ROS and RNS sources in physiological and pathological conditions. Oxid Med Cell Longev. 2016; 2016:1245049.

5. Kurutas EB. The importance of antioxidants which play the role in cellular response against oxidative/nitrosative stress: current state. Nutrition J. 2016; 15:17.

6. Libetta C, Sepe V, Esposito P, Galli F, Dal Canton A. Oxidative stress and infammation: implications in uremia and hemodialysis. Clin Biochem. 2011; 44:1189-1198.

7. Liguori I, Russo G, Curcio F, Bulli G, Aran L, Della-Morte D, et al. Oxidative stress, aging, and diseases. Clin Interv Aging. 2018;13:757-772.

8. Hille R, Nishino T. Xanthine oxidase and xanthine deshydrogenase. FASEB J. 1995; 9:995-1003.

9. Harrison R. Milk xanthine oxidase: properties and physiological roles. Intern Dairy J. 2006; 16:546-554.

10. Saches L, Batffra KL, Zimmermann B. Medical implications of hyperuricemia. Med Health. 2009; 92:353-355.

11. Pacher P, Nivorozhkin A, Szabo C. Therapeutic effects of xanthine oxidase inhibitors: renaissance half a century after the discovery of allopurinol. Pharmacol Rev. 2006; 58:87-114.

12. Demain AL, Sanchez S. Microbial drug discovery: 80 years of progress. J Antibiot. 2009; 62:5-16.

13. Aslam B, Wang W, Arshad MI, Khurshid M, Muzammil S, Rasool $\mathrm{MH}$, et al. Antibiotic resistance: a rundown of a global crisis. Infect Drug Resist. 2018; 11:1645-1658.

14. Quezel P, Santa S. Nouvelle flore de l' Algerie et des régions desertiques méridionales. Paris : Centre National de la Recherche Scientifique;1963. p 658-659.

15. Baghiani A, Harrison R, Benboubetra M. Purification and partial characterisation of camel milk xanthine oxidoreductase. Arch Physiol Biochem. 2003; 111:407-414.

16. Venton AM, Deistung J, Bray RC. The isolation of demolybdo xanthine oxidase from bovine milk. Biochem J. 1988; 255:949956.

17. Bray RC. Molybdenum iron-sulfur flavin hydroxylases and related enzymes. In : Boyer PD, editor. The enzyme. New York : Academic Press; 1975. p 299-419.

18. Laemmli UK. Cleavage of structural proteins during the assembly of the head of bacteriophage T4. Nature.1970; 227:680-685.

19. Avis P, Bergel F, Bray RC, James DWF, Shooter K. Cellular constituent, the chemistry of xanthine oxidase, Part II, The homogeneity of crystalline metalloflavoprotein. J chem Soci. 1959; Resumed: 1212-1219. 
20. Markham KR. Techniques of flavonoid identification (Chapter 1 and 2). London : Academic Press; 1982. p 1-113.

21. Li HB, Cheng KW, Wong CC, Fan KW, Chen F, Jiang Y. Evaluation of antioxidant capacity and total phenolic content of different fractions of selected microalgae. Food Chem. 2007; 102:771776.

22. Bahorun T, Gressier B, Trotin F, Brunete C, Dine T. Oxigen species scavenging activity of phenolic extract from howthorn fresh plant organs and pharmaceutical preparation. Arzneimittel-forschung. 1996; 46:1086-1094.

23. Boumerfeg S, Baghiani A, Messaoudi D, Khennouf S, Arrar L. Antioxidant Properties and Xanthine Oxidase Inhibitory Effects of Tamus communis L. Root Extracts. Phytother Res. 2009; 23:283-288.

24. Robak J, Gryglewski RJ. Flavonoids are scavengers of superoxide anions. Biochem Pharmacol. 1988; 37:837-841.

25. Ani V, Varadaraj MC, Akhilender Naidu K. Antioxidant and antibacterial activities of polyphenolic compounds from bitter cumin (Cuminum nigrum L.). Europ food Res technol. 2006; 224:109-115.

26. Aslan A, Güllüce $M$, Sôkmen $M$, Adigüzel A, Sahin F, Özkan H. Antioxidant and antimicrobial properties of the lichens Cladonia foliacea, Dermatocarpon miniatum, Everinia divaricata, Evernia prunastri, and Neofuscella pulla. Pharm Biol. 2006; 44:247-252.

27. Cuendet M, Hostettmann K, Dyatmiko W, Potterat O. Iridoid glucosides with free radical scavenging propreties from Fagraea blumei. Helvitica Chimica Acta. 1997; 80:1144-1152.

28. Decker EA,Welch . Role of ferritin as a lipid oxidation catalyst in muscle food. J Agric Food Chem. 1990; 38:674-677.

29. Le $\mathrm{K}$, Chiu F, Ng K. Identification and quantification of antioxidants in Fructus lycii. Food Chem. 2007; 105:353-363.

30. Benzie IF, Strain JJ. The ferric reducing ability of plasma (FRAP) as a measure of "antioxidant power": the FRAP Assay. Anal Biochem. 1996; 239:70-76.

31. Pulido R, Bravo L, Saura-Calixto F. Antioxidant activity of dietary polyphenols as determined by a modified ferric reducing/antioxidant power assay. J Agric Food Chem. 2000; 40:3396-3402.

32. Baghiani A, Boussoualim N, Trabsa H, Aouachria S, Arrar L. In Vivo free radical scavenging, antihemolytic activity and antibacterial effects of Anchusa Azurea extracts. Int J Med Med Sci. 2016; 46:1114-1118.

33. Fitriansyah SN, Fidrianny I, Ruslan K. Correlation of total phenolic, flavonoid and carotenoid content of sesbania sesban (1 merr) leaves extract with DPPH scavenging activties. Int J Pharmacogn Phytochem Res.2017; 9:89-94.

34. Boussoualim N, Krache I, Baghiani A, Trabsa H, Aouachria S, Arrar L. Human xanthine oxidase inhibitory effect, antioxidant in vivo of algerian extracts (Globularia alypum L.). Int J Pharmacogn Phytochem Res. 2016; 8:645-650.

35. Wu N, Zu Y, Fu Y, Kong Y, Zhao J, Li X, et al. Antioxidant activities and xanthine oxidase inhibitory effects of extracts and main polyphenolic compounds obtained from Geranium sibiricum L. J Agric Food Chem. 2010; 58:4737-4743.

36. Cos P, Ying L, Calomme M, Hu JP, Cimanga K, Van Poel B, et al. Structure activity relationship and classification of flavonoids as inhibitors of xanthine oxidase and superoxide scavengers. J Natur Prod. 1998; 61:71-76.

37. Mandade R, Sreenivas SA, Choudhury A. Radical scavenging and antioxidant activity of Carthamus tinctorius extracts. Free Radic Antiox. 2011; 1:87-93.

38. Naidu MM, Shyamala BN, Naik JP, Sulochanamma G, Srinivas P. Chemical composition and antioxidant activity of the husk and endosperm of fenugreek seeds. Lebenson Wiss Technol. 2011; 44:451-456.

39. Pandey G, Khatoon S, Pandey, Rawat AKS. Altitudinal variation of berberine, total phenolics and flavonoid content in Thalictrum foliolosum and their correlation with antimicrobial and antioxidant activities. J Ayurveda Integr Med. 2018; 9:169-176.

40. Nur Arina AJ, Azrina A. Comparison of phenolic content and antioxidant activity of fresh and fried local fruits. Inter Food Res J. 2016; 23:1717-1724.

41. Othman A, Mukhtar NJ, Ismail NI, Chang SK. Phenolics, flavonoids content and antioxidant activities of 4 Malaysian herbal plants. Inter Food Res J. 2014; 21:759-766.

42. Sahreen S, Khan, Khan RA. Evaluation of antioxidant profile of various solvent extracts of Carissa opaca leaves: an edible plant. Chem Centrl J. 2017; 11:83.

43. Saha S, Verma RJ. Antioxidant activity of polyphenolic extract of Terminalia chebula Retzius fruits. J Taibah Univ Sci. 2016; 10:805-812.

44. Anwar F, Shaheen N, Shabir G, Ashraf M, Alkharfy KM, Gilani AH Variation in antioxidant activity and phenolic and flavonoid contents in the flowers and leaves of Ghaneri (Lantana camara L) as affected by different extraction solvents. Inter J Pharmacol. 2013; 9:442-453.

45. Sahreen S, Khan MR, Khan RA. Evaluation of antioxidant activities of various solvent extracts of Carissa opaca fruits. Food Chem. 2010; 122:1205-1211.

46. Fernandez MT, Mira ML, Florêncio MH, Jennings KR. Iron and copper chelation by flavonoids: an electrospray mass spectrometry study. J Inor Biochem. 2002; 92:105-111.

47. Papuc G, Goran GV, Predescu CN, Nicorescu V, Stefan G. Plant polyphenols as antioxidant and antibacterial agents for shelf-life extension of meat and meat products: classification, structures, sources, and action mechanisms. Compr Rev Food Sci Food Saf. 2017; 16:1243-1268.

48. Esmaeili AK, Taha RM, Mohajer S, Banisalam B. Antioxidant activity and total phenolic and flavonoid content of various solvent extracts from in vivo and in vitro grown Trifolium pratense L. (red clover). BioMed Res Inter. 2015; 2015:643285.

49. Borneo R, León AE, Aguirre A, Ribotta A, Cantero JJ. Antioxidant capacity of medicinal plants from the Province of Córdoba (Argentina) and their in vitro testing in a model food system. Food Chem1. 2009; 12:664-670.

50. Loganayaki N, Siddhuraju P, Manian S. Antioxidant activity and free radical scavenging capacity of phenolic extracts from Helicteres isora L. and Ceiba pentandra L. J Food Sci Technol. 2013; 50:687-695.

51. Harries AD, Kumar AMV, Satyanarayana S, Lin Y, Takarinda K C, Tweya $\mathrm{H}$, et al. Communicable and non-communicable diseases: connections, synergies and benefits of integrating care. Public Health Action. 2015; 5:156-157. 